\title{
Production of dextran and fructose from carob pod extract and cheese whey by Leuconostoc mesenteroides NRRL B512(f)
}

\author{
Mariana Santos $^{\mathrm{a}}$, Alírio Rodrigues ${ }^{\mathrm{b}}$, José A. Teixeira ${ }^{\mathrm{a}, *}$ \\ ${ }^{a}$ Centro de Engenharia Biológica, Campus de Gualtar, 4710-057 Braga, Portugal \\ ${ }^{\mathrm{b}}$ Laboratory of Separation and Reaction Engineering, Departamento de Engenharia Química, \\ Faculdade de Engenharia da Universidade do Porto, Rua Dr. Roberto Frias s/n, 4200-465 Porto, Portugal
}

Received 8 July 2003; received in revised form 11 January 2005; accepted 12 January 2005

\begin{abstract}
The production of dextran and fructose from carob pod extract (CPE) and cheese whey $(\mathrm{CW})$ as carbon source by the bacterium Leuconostoc mesenteroides was investigated. The influence of secondary carbon sources (maltose, lactose and galactose) on dextran molecular weight and fermented broth viscosity were also studied.

Significant changes were not observed in broth viscosity during dextran production at initial sucrose concentration of 20 and $120 \mathrm{~g} / \mathrm{l}$. Complementary sugars maltose, lactose and galactose together with sucrose promote production of dextran with fewer glucose units. Dextran molecular weight decreases from the range 1,890,000-10,000,000 to 240,000-400,000 Da when complementary sugars are present. Polydispersity was improved when complementary sugars were used.

Fermentation using mixtures of carob pod extract and cheese whey confirm these results obtained for production of dextran. Final concentrations of dextran and fructose indicate that reaction yields were not affected. Carob pod and cheese whey can be successfully used as raw material in the fermentation system described.

The maximum concentrations of dextran and fructose obtained using carob pod extract resulted in 8.56 and $7.78 \mathrm{~g} / \mathrm{l}$, respectively. Combined carob pod extract and cheese whey resulted in dextran and fructose concentrations of 7.23 and $6.98 \mathrm{~g} / 1$, respectively. The corresponding dextran mean molecular weight was $1,653,723$ and 325,829 .
\end{abstract}

(C) 2005 Published by Elsevier B.V.

Keywords: Dextran; Fructose; Leuconostoc mesenteroides; Viscosity; Molecular weight; Carob pod; Cheese whey

\section{Introduction}

Dextran is a D-glucose polymer composed of 95\% $\alpha(1 \rightarrow 6)$ linkages in the linear chain. Commercial applications for dextran are generally in the pharmaceutical industry, but new applications are being considered in the food and textile industries [1,2]. Dextran for human applications usually is produced by Leuconostoc mesenteroides NRRL B512(f) [3]. The bacterium is grown in a sucrose-rich media releasing an enzyme, dextransucrase, which converts excess sucrose to dextran and fructose [4]. When high sucrose concentra-

\footnotetext{
* Corresponding author. Tel.: +351253 604400; fax: +351253678986.

E-mail address: jateixeira@deb.uminho.pt (J.A. Teixeira).
}

tion is used to produce dextran and fructose, broth viscosity becomes high and process control becomes more difficult. Acceptor molecules, such as maltose present in the culture media can influence dextran molecular weight by allowing the growing chain to be separated from the enzyme active site and transferred to the acceptor [5-7].

A reduction in dextran molecular weight was observed [8] together with less viscous and more Newtonian solutions, when working at lower temperatures. However, Choplin and Sabatie [9] showed that dextran produced at lower temperatures was less branched and as a result more viscous.

The rheological behaviour of the broth depends on the species of microorganism being cultured and on the process 
conditions. Several authors $[10,11,9]$ studied the rheological behaviour of cultures of Leuconostoc mesenteroides rich in dextran. Different results were obtained for different strains and process conditions.

Carob (Ceratonia siliqua) is a perennial leguminous tree, native to the Mediterranean basin and Southwest Asia. It has been cultivated throughout the Mediterranean region for approximately 4000 years. Portugal and Spain have approximately 100,000 ha of carob trees and process approximately half of the world's commercial carob supply. World carob pod production is approximately $315,000 \mathrm{t}$ per year and the main carob bean producers and exporters are Spain (42\%), Italy (16\%), Portugal (10\%), Morocco (8\%), Greece (6.5\%), Cyprus (5.5\%) and Turkey (4.8\%) [12].

Carob is drought-resistant, requires little maintenance and produces a range of products from the seed and the pod. The endosperm is extracted from the seeds to produce a galactomannan, which forms locust bean gum, a valuable natural food additive used also in textile and cosmetic industries. The pod is useful for high-energy stock feed and the human food industry as a cocoa substitute and in syrups. Carob pod is also an anti-diarrheic product [13] because of its high tannin content.

Avallone et al. [14] determined carob pod composition. High content of carbohydrates $(45 \%$, sucrose at more than $30 \%$ ), appreciable amounts of protein (3\%) and low levels of fat $(0.6 \%)$ were found. High tannin content is also present in carob pod composition, which limits the consumption by cattle because of reduced digestibility [15].

Research has been carried out [16-18] fermenting carob pod extract to produce high-value products. However, dextran and fructose production using carob pod extract has not been investigated and may have substantial benefits.

Another potential area of economic benefit is new uses of milk sugar, which presents a challenge to dairy research and the industry. Indeed, the market for lactose in the pharmaceutical industry is over-saturated and all the routes to chemically modify this sugar in products, such as lactulose, lactitol and detergents involve only small markets. The dairy industry worldwide is investigating markets for by-products containing high lactose content, such as whey. The worldwide lactose surplus is actually $550,000 \mathrm{t}$ per year [19]. Environmental constraints fully justify discouraging direct discharge of such a large amount witch has the equivalent polluting potential of 18 million people. The potential to create economical value from lactose containing liquids exists by fermentation.

The aim of the present investigation was to study the production of dextran and fructose from carob pod extract and cheese whey. Also, the influence of acceptors (maltose, lactose and galactose) on the molecular weight of dextran was studied.

\section{Materials and methods}

\subsection{Microorganism and inoculum}

The strain used in this work was Leuconostoc mesenteroides NRRL B512(f) obtained from DSM (Deutsche Sammlung von Mikroorganismen und Zellkulturen $\mathrm{GmbH}$ ) in freeze-dried vials. Inoculum preparation is described elsewhere [20].

\subsection{Fermentation experiments}

The composition of the fermentation medium used to study the effect of initial sucrose concentration on the rheology of the fermentation broth was as follows: sucrose $(20$ or $120 \mathrm{~g} / \mathrm{l})$, yeast extract $(7 \mathrm{~g} / \mathrm{l})$ and $\mathrm{K}_{2} \mathrm{HPO}_{4}(8 \mathrm{~g} / \mathrm{l})$. The $\mathrm{pH}$ of the medium was adjusted, using $\mathrm{HCl} 4 \mathrm{M}$, to the value required prior to autoclaving $\left(15 \mathrm{~min}\right.$ at $\left.121^{\circ} \mathrm{C}\right)$.

To assay the influence of complementary sugars on dextran properties, four different experiments were carried out in order to produce dextran with different molecular weight. The first fermentation run was a typical fermentation as described elsewhere [20] with sucrose as substrate.

The other three runs were similar to the first one, but a second carbon source was added to the media together with sucrose. The complementary sugars used were maltose, lactose and galactose at $0.5 \%(\mathrm{w} / \mathrm{v})$.

To test dextran production using carob pod extract and cheese whey as substrates batch fermentation runs were carried out using (a) carob pod extract (CPE) (approximately $20 \mathrm{~g} / \mathrm{l}$ of sucrose initial concentration) with yeast extract ( $4 \mathrm{~g} / \mathrm{l})$, and (b) CPE (approximately $20 \mathrm{~g} / \mathrm{l}$ of sucrose initial concentration) complemented with yeast extract $(4 \mathrm{~g} / \mathrm{l})$ and a percentage of cheese whey $(\mathrm{CW})$ to obtain $5 \mathrm{~g} / \mathrm{l}$ of lactose in the fermentation medium $(\mathrm{CPE}+\mathrm{CW})$. Yeast extract was added as no biomass growth occurs in pure carob pod extract. Appropriate dilutions were made in order to adjust sucrose and lactose initial concentrations of the media (CPE or $\mathrm{CPE}+\mathrm{CW}$ ). To prepare 31 of a $20 \mathrm{~g} / \mathrm{l}$ initial sucrose concentration extract, $645 \mathrm{ml}$ of carob pod extract were used on a 51 working volume batch reactor. To prepare 31 of a $20 \mathrm{~g} / \mathrm{l}$ initial sucrose concentration and $5 \mathrm{~g} / \mathrm{l}$ initial lactose concentration extract, $645 \mathrm{ml}$ of CPE were mixed with $234 \mathrm{ml}$ of autoclaved cheese whey and with $2121 \mathrm{ml}$ of distilled water.

\subsection{Bioreactor}

A 51 bioreactor (Braun, Biostat ${ }^{\circledR} \mathrm{MD}$ ) was used to perform all experiments. A MCU-200 unit was used to perform agitation and acid/base addition to the fermentation media. A micro DCU-Twin unit was used to monitor the fermentation experiment. Temperature control was by an external bath. The process conditions used are as described by Santos et al. [20]. 


\subsection{Carob pod extract preparation}

Carob pod residues from the galactomannan industry were supplied by Indal (Algarve, Portugal). Carob pods were received in small particles $(0.5 \mathrm{~cm} \times 0.5 \mathrm{~cm} \times 0.25 \mathrm{~cm})$ and reduced to flour with a hammer mill (Retschmuhle).

Sucrose extraction was carried out by mixing $100 \mathrm{~g}$ of carob pod flour with $400 \mathrm{ml}$ of an acetic acid/sodium acetate buffer $\mathrm{pH}$ 7.4. The temperature was $70^{\circ} \mathrm{C}$ and agitation was $100 \mathrm{rpm}$. After the first hour, samples were centrifuged at $4{ }^{\circ} \mathrm{C}$ and $8000 \mathrm{rpm}$ for $10 \mathrm{~min}$. Sucrose, glucose and fructose concentrations were 93, 32 and $29 \mathrm{~g} / \mathrm{l}$, respectively.

Carob pod flour has a high content of tannins that can be transferred to aqueous phase during sugar extraction. This must be prevented because they inhibit bacterial growth; acetic acid/sodium acetate buffer $\mathrm{pH} 7.4$ was used to control tannin dissolution on the aqueous phase.

\subsection{Cheese whey preparation}

Cheese whey was obtained from a cheese company ("Quinta dos Inglêses", Braga, Portugal), pH upon reception being 5.0. Proteins were precipitated by autoclaving whey for $15 \mathrm{~min}$ at $121^{\circ} \mathrm{C}$ and removed by centrifugation at $4^{\circ} \mathrm{C}$ and $8000 \mathrm{rpm}$ for $10 \mathrm{~min}$. Supernatant contained $64 \mathrm{~g} / \mathrm{l}$ of lactose.

\subsection{Bacterial growth determination}

Bacterial growth was followed by UV spectrophotometry $(660 \mathrm{~nm})$. A calibration curve of dry weight versus o.d. $(660 \mathrm{~nm})$ was used to determine biomass concentration (g biomass/l). Bacterial growth was determined as optical density because of numerous contaminants suspended in the carob pod extract culture media that causes difficulties in dry weight biomass determination.

In order to avoid any influence of the material in suspension in o.d. values of the fermented broth, all the obtained values were subtracted by the initial o.d. value of culture media (before inoculation was done).

\subsection{Sugar analysis}

The levels of sugar in carob pod extract and cheese whey and the concentrations of residual sugar and products were determined by HPLC with RI detection. An ion-exchange column (Interaction, model 300) was used. Solvent was $\mathrm{H}_{2} \mathrm{SO}_{4} 0.005 \mathrm{~N}$ and flow rate was $0.3 \mathrm{ml} / \mathrm{min}$.

Dextransucrase activity was assayed by measuring the amount of sucrose consumed. One dextransucrase unit (1 DSU) was defined as the amount of enzyme that converts $1 \mathrm{mg}$ of sucrose in $1 \mathrm{~h}$ under ideal reaction conditions $\left(T=30^{\circ} \mathrm{C} ; \mathrm{pH}\right.$ 5.0) [4]. Samples were centrifuged at $5000 \mathrm{rpm}$ for $5 \mathrm{~min}$ to remove biomass before analysis.

\subsection{Viscosity study}

A moving body viscometer $\left(\right.$ Gilmont $\left.{ }^{\circledR}\right)$ was used. Here, the movement of a sphere through the sample is studied-Stokes law [21]:

$\eta=\frac{2 r^{2} g\left(\rho_{s}-\rho_{l}\right)}{9 v}$

where $\eta$ is viscosity, $r$ the sphere radius, $\rho_{\mathrm{s}}$ and $\rho_{1}$ the sphere and liquid density, respectively; $g$ is gravitational force and $v$ sphere velocity.

Generalised Stokes law can be written as:

$\eta=\frac{k\left(\rho_{s}-\rho_{l}\right)}{v}$

where $k$ is the instrument constant, measured by calibration with standard fluids.

The instrument equation for viscosity is:

$\eta=K \times\left(\rho_{s}-\rho_{l}\right) \times t$

where $\eta$ is viscosity in centipoises (cp), $\rho_{\mathrm{s}}$ the glass sphere density $(2.53 \mathrm{~g} / \mathrm{ml}), t$ the time ( $\mathrm{min})$ that the sphere takes to reach the bottom of the sample and $K$ the viscometer constant $(K=3.3 \mathrm{cp} \mathrm{ml} / \mathrm{g} / \mathrm{min})$.

Samples were collected every $2 \mathrm{~h}$ till the end of fermentation and viscosity was measured at $26^{\circ} \mathrm{C}$.

\subsection{Characterisation of dextran molecular weight}

Size exclusion chromatography (SEC) was used to characterise the molecular size distribution of dextran [22]. The column used was a NUCLEOGEL GFC 4000-8 (MachereyNagel) on a system equipped with a refractive index detector. The column was previously calibrated using dextran of different molecular weight (Sigma). Samples were collected during fermentation runs and centrifuged in order to remove cellular mass.

Operating conditions were $T=26^{\circ} \mathrm{C}$ and $\mathrm{pH} 7$; the eluent was pure water at $1 \mathrm{ml} / \mathrm{min}$. Fig. 1 presents the calibration curve obtained by Eq. (4):

$\mathrm{Mw}=1.27 \times 10^{17} V_{e}^{-14.88}$

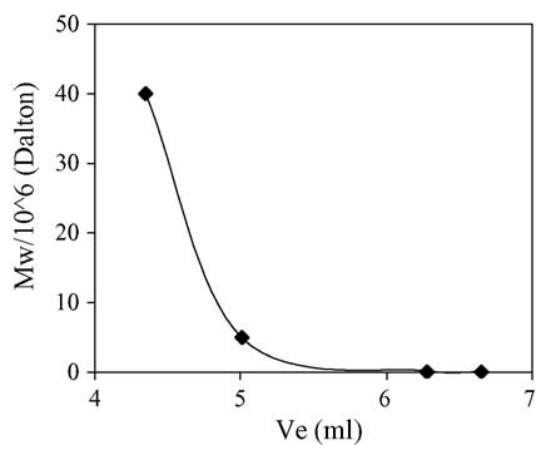

Fig. 1. Calibration of gel filtration chromatography column with dextran solutions of different molecular weight; Mw vs. volume eluted $\left(V_{e}\right)$. 


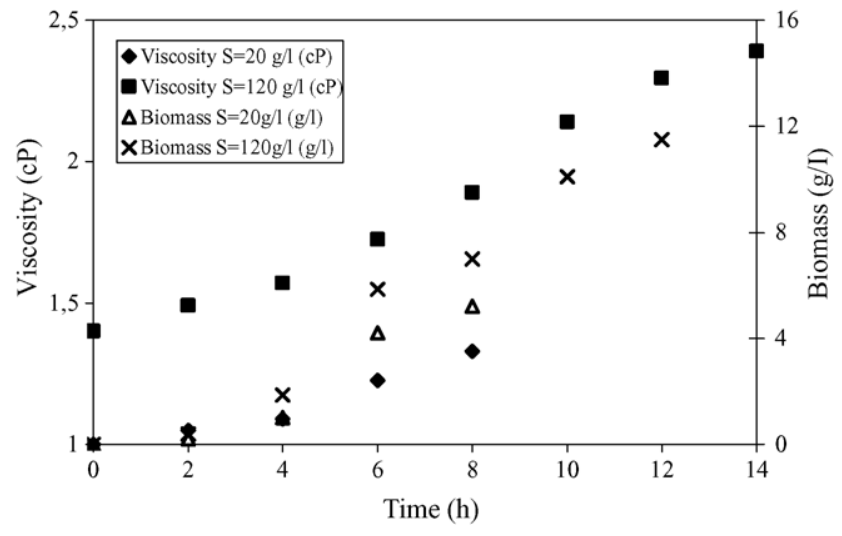

Fig. 2. Variation of biomass concentration and fermentation supernatant viscosity for fermentations with initial sucrose concentration of 20 and $120 \mathrm{~g} / \mathrm{l}$.

where Mw is molecular weight in Dalton and $V_{e}$ the elution volume in $\mathrm{ml}$.

Dextran samples from fermentation were passed through the column and a study on the distribution of obtained molecular weight was done [23]. From Eqs. (5) and (6), mean molecular weight in number $(\overline{M n})$ and mean molecular weight in mass $(\overline{M w})$ were calculated. Polydispersity $(Q)$ was calculated as being the ratio $\overline{M w} / \overline{M n}$.

$\overline{M n}=\frac{\int y \mathrm{~d} V_{e}}{\int(y / M w) \mathrm{d} V_{e}}$

$\overline{M w}=\frac{\int M w \times y \mathrm{~d} V_{e}}{\int y \mathrm{~d} V_{e}}$

$Q=\frac{\overline{M w}}{\overline{M n}}$

In Eqs. (5) and (6), $y$ represents the chromatogram signal in $\mathrm{mV}$.

\section{Results and discussion}

\subsection{Effect of sucrose concentration on the viscosity of the fermentation broth}

Landon et al. [11] concluded that fermented broth with $10 \mathrm{~g} / \mathrm{l}$ of dextran and cell concentration between 5 and $10 \mathrm{~g} / \mathrm{l}$ shows a Newtonian behaviour.

Process conditions were determined elsewhere [20] and the sucrose concentration used was $20 \mathrm{~g} / \mathrm{l}$. For this initial amount of sucrose, final dextran and cell concentration will never be over $10 \mathrm{~g} / \mathrm{l}$ and so we are in presence of a Newtonian solution and the viscosity study is simplified.

Fig. 2 demonstrate that for the operating conditions used in this study, the viscosity is not much affected suffering a small variation from the beginning to the end of the fermentation.

These results are very important because potential rheological problems will not occur if fermentations are performed at the same conditions. Expensive powerful agitation systems are not needed to promote homogenisation of these fermentation units.

\subsection{Effect of complementary sugars on dextran properties}

The presence of complementary sugars on fermentation media causes a reduction on dextran molecular weight from the moment polymer starts being produced, leading also to higher values of polydispersity (Table 1). The smallest values for dextran molecular weight were obtained for maltose as an acceptor, followed by lactose and galactose. It can also be seen that the acceptor molecules improve $Q$ from 1.87 for fermentation with sucrose only, to a maximum value of 7.85 for fermentation with sucrose and lactose or galactose.

However, dextran and fructose production is not considerably affected by acceptor molecules. Complementary sugars allow the growing chain to be separated from the enzyme active site and transferred to the acceptor reducing size of dextran molecules.

None of the three complementary sugars is consumed by the bacteria and fermentation time varies between 8 and $10 \mathrm{~h}$. In the presence of lactose, dextransucrase production is strongly inhibited (less $40 \%$ enzyme being produced), but dextran and fructose final yield is maintained.

\subsection{Dextran and fructose production using carob pod extract and cheese whey}

The main point of the work presented in this section was to produce lower molecular weight dextran using agroindustrial residues. This is an important issue, because companies have to deal with the residues they are producing; re-using them is an optimal solution.

Samples were collected every $2 \mathrm{~h}$ along fermentation and treated as described elsewhere [20]. Results of both fermentations can be observed on Figs. 3 and 4. Biomass growth is smaller and sucrose consumed is higher in presence of lac-

Table 1

Calculated values of $\overline{M w}, \overline{M n}, Q$ and Mw intervals obtained in each one of the fermentations carried out with complementary sugars

\begin{tabular}{|c|c|c|c|c|c|c|c|c|c|}
\hline Sugar & $t(\mathrm{~h})$ & $B(\mathrm{~g} / \mathrm{l})$ & $\mathrm{D}(\mathrm{g} / \mathrm{l})$ & $\mathrm{F}(\mathrm{g} / \mathrm{l})$ & $E(\mathrm{DSU} / \mathrm{ml})$ & $\overline{M w}$ & $\overline{M n}$ & $Q$ & Mw interval \\
\hline Maltose & 8 & 5.73 & 7.66 & 7.79 & 49.73 & 240,800 & 35,800 & 6.72 & $3,440,651-7941$ \\
\hline Lactose & 10 & 4.8 & 6.88 & 7.00 & 30.64 & 311,700 & 39,700 & 7.85 & $7,294,851-8209$ \\
\hline Galactose & 10 & 5.58 & 7.08 & 7.37 & 52.74 & 398,500 & 34,000 & 7.85 & $9,255,139-6740$ \\
\hline Sucrose only & 10 & 6.04 & 7.48 & 7.19 & 55.28 & $1,890,500$ & $10,000,000$ & 1.87 & $14,677,264-183,127$ \\
\hline
\end{tabular}

Final concentration of biomass $(B)$, dextran $(D)$, fructose $(F)$, enzyme activity $(E)$ and fermentation time $(t)$ are also reported. 
Table 2

Calculated values of $\overline{M w}, \overline{M n}, Q$ and Mw intervals obtained in each one of the fermentations carried out with carob pod extract (CPE) and carob pod extract enriched with cheese whey $(\mathrm{CPE}+\mathrm{CW})$

\begin{tabular}{llllllllll}
\hline Sugar & $t(\mathrm{~h})$ & $B($ o.d. $\times 10)$ & $\mathrm{D}(\mathrm{g} / \mathrm{l})$ & $\mathrm{F}(\mathrm{g} / \mathrm{l})$ & $E(\mathrm{DSU} / \mathrm{ml})$ & $\overline{M w}$ & $\overline{M n}$ & $Q$ & $\mathrm{Mw}$ interval \\
\hline CPE & 12 & 5.82 & 8.56 & 7.78 & 53.2 & $1,653,723$ & $8,981,231$ & 1.84 & $12,845,641-190,837$ \\
$\mathrm{CPE}+\mathrm{CW}$ & 12 & 5.07 & 7.23 & 6.98 & 29.5 & 325,829 & 43,322 & 7.52 & $7,875,371-8879$ \\
\hline
\end{tabular}

Final concentration of biomass $(B)$, dextran (D), fructose $(\mathrm{F})$, enzyme activity $(E)$ and fermentation time $(t)$ are also reported.

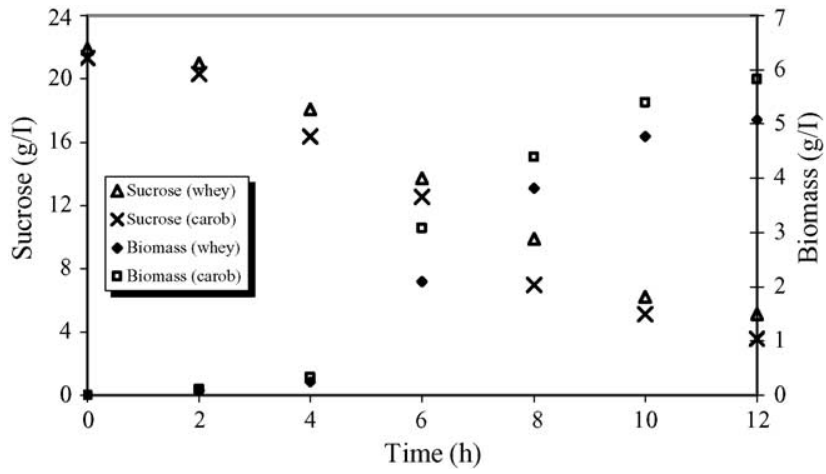

Fig. 3. Biomass and sucrose consumption during fermentation using carob pod extract and a mixture of carob pod extract and cheese whey.

tose. Lesser quantities of biomass indicate lesser extracellular enzyme produced. Once more, data analysis (Fig. 4) shows a clear inhibition of dextransucrase synthesis in presence of lactose, around $40 \%$ fewer enzymes produced. Lopretti et al. [24] have already concluded this but the main issue is to produce dextran, and biopolymer production levels are good as we can observe by analysis of both Tables 1 and 2. Enzyme produced is then enough to break glucose-fructose linkages in sucrose, liberating fructose and producing dextran. Samples collected at the end of both fermentations were used to study dextran properties. Table 2 shows these results.

Confirming studies of previous section of this work, dextran molecular weight is considerably lower when produced in presence of lactose as a complementary sugar in fermentation media. Mean molecular weight in mass found was $1,653,723$ when carob pod extract (CPE) was used, and 325,829 when cheese whey was added to the carob pod ex-

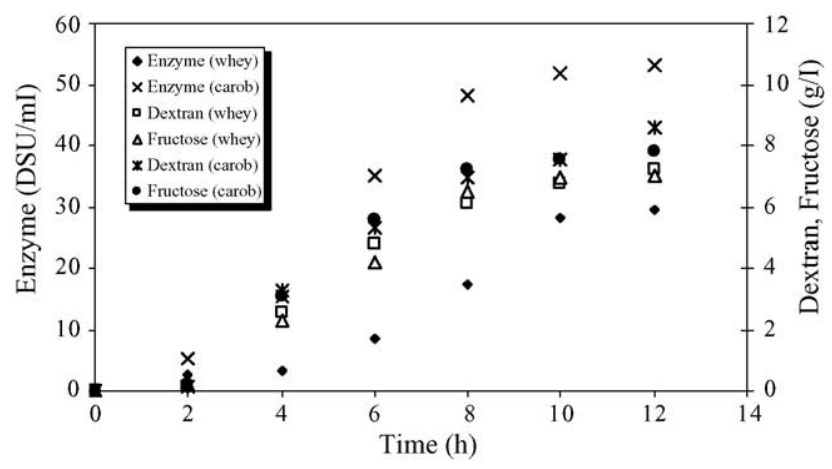

Fig. 4. Dextransucrase, dextran and fructose production during fermentation using carob pod extract and a mixture of carob pod extract and cheese whey. tract $(\mathrm{CPE}+\mathrm{CW})$. It is important to notice that these values are of the same order of magnitude of those obtained when pure sugars were used in the culture medium (Table 1).

\section{Conclusions}

From the study of viscosity we conclude that for sucrose concentration of 20 and $120 \mathrm{~g} / \mathrm{l}$, the viscosity broth does not have a strong negative impact on homogenisation when scaling up dextran and fructose production.

Controlling dextran molecular weight with manipulation of fermentation media composition is very important. Lower costs to hydrolyse long dextran chains to shorter ones may be obtained using complementary sugars in fermentation media.

On the studied cases, dextran molecular weight fell from the range of $1,890,000-10,000,000 \mathrm{Da}$ using only sucrose to values between 240,000 and $400,000 \mathrm{Da}$, when using other sugars together with sucrose. A wider range of dextran molecular weights implies higher polydispersity values. Lactose is an enzyme production inhibitor but final dextran and fructose yield is maintained, so if the objective is to produce dextransucrase together with dextran, complementary sugars may be optimal.

L. mesenteroides NRRL B512(f) grows and produces the extra-cellular enzyme dextransucrase and also dextran and fructose on carob pod extract and cheese whey. In presence of cheese whey lactose, dextran produced is also of a lower molecular weight.

\section{References}

[1] H.J. Koepsell, H.M. Tsuchiya, Enzymatic synthesis of dextran, J. Bacteriol. 63 (1952) 293-295.

[2] T.R. Shamala, M.S. Prasad, Preliminary studies on the production of high and low viscosity dextran by Leuconostoc spp., Process Biochem. 30 (1995) 237-241.

[3] P.E. Barker, N.J. Ajongwen, The production of the enzyme dextransucrase using nonaerated fermentation techniques, Biotechnol. Bioeng. 37 (1991) 703-707.

[4] H.M. Tsuchiya, H.J. Koepsell, J. Corman, M.O. Bryant, V.H. Feger, R.W. Jackson, The effect of certain cultural factors on production of dextransucrase by Leuconostoc mesenteroides, J. Bacteriol. 64 (1952) 521-526.

[5] J.F. Robyt, T.F. Walseth, The mechanism of acceptor reactions of Leuconostoc mesenteroides NRRL B-512F dextransucrase, Carbohydr. Res. 61 (1978) 433-445.

[6] J.F. Robyt, S.H. Eklund, Relative, quantitative effects of acceptors in the reaction of Leuconostoc mesenteroides NRRL B-512F dextransucrase, Carbohydr. Res. 121 (1983) 279-286. 
[7] M. Dols, M. Remaud-Simeon, R. Willemot, M. Vignon, P. Monsan, Structural characterisation of the maltose acceptor-products synthesised by Leuconostoc mesenteroides NRRL B1299 dextransucrase, Carbohydr. Res. 305 (1998) 549-559.

[8] A. Tecante, A. Lopez-Munguia, A. Garcia-Rejon, Rheological characterisation of dextran-enzymatic synthesis media, J. Appl. Polym. Sci. 31 (1986) 2337-2350.

[9] L. Choplin, J. Sabatie, The effect of synthesis temperature on the rheological properties of native dextran, Biotechnol. Lett. 6 (1986) 425-430.

[10] V.B. Veljkovic, M.L. Lazic, D.J. Rutic, S.M. Jovanovic, D.U. Skala, Effects of aeration on extracellular dextransucrase production by Leuconostoc mesenteroides, Enzyme Microb. Technol. 14 (1992) 665-668.

[11] R.S. Landon, R.C.S. Law, C. Webb, Fermentation broth rheology during dextran production by Leuconostoc mesenteroides B512(f), Appl. Microbiol. Biotechnol. 40 (1993) 251-257.

[12] R. Fletcher, Carob agroforestry in Portugal and Spain, The Australian New Crops Newsletter, Issue No. 7, 1997 (http://www.newcrops.uq. edu.au/newslett/ncnl7-13.htm).

[13] H. Loeb, Y. Vandenplas, P. Wursch, P. Guesry, Tannin-rich carob pod for the treatment of acute-onset diarrhea, J. Paediatr. Gastroenterol. Nutr. 8 (4) (1989) 480-485.

[14] R. Avallone, M. Plessi, M. Baraldi, A. Monzani, Determination of chemical composition of carob (Ceratonia siliqua): protein, fat, carbohydrates and tannins, J. Food Compos. Anal. 10 (1997) 166-172.

[15] A. Priolo, G.C. Waghorn, M. Lanza, L. Biondi, P. Pennisi, Polyethylene glycol as a means for reducing the impact of condensed tannins in carob pulp: effects on lamb growth, performance and meat quality, J. Anim. Sci. 78 (2000) 810-816.

[16] T. Roukas, Solid-state fermentation of carob pods for ethanol production, Appl. Microbiol. Biotechnol. 41 (1994) 296301 .

[17] T. Roukas, Ethanol production from carob pod extract by immobilized Saccharomyces cerevisiae biomass on the mineral kissiris, Food Biotechnol. 9 (1995) 175-188.

[18] T. Roukas, Citric acid production from carob pod extract by cell recycle of Aspergillus niger ATCC, 9142, Food Biotechnol. 12 (1998) 91-104.

[19] E.V. Lifran, J.A. Hourigan, R.W. Sleigh, R.L. Johnson, Food processing future trends, Food Aust. 52 (2000) 4.

[20] M. Santos, J. Teixeira, A. Rodrigues, Production of dextransucrase, dextran and fructose from sucrose using Leuconostoc mesenteroides NRRL B512(f), Biochem. Eng. J. 4 (2000) 177-188.

[21] J. Kroschwitz, Polymers: Polymer Characterisation and Analysis, Jonh Wiley and Sons, USA, 1990.

[22] C.E. Lundy, R.D. Hester, Characterisation of large water-soluble macromolecules by size exclusion chromatography, J. Polym. Sci., Part A: Polym. Chem. 24 (1986) 1829-1838.

[23] F.W. Billmeyer, Text Book of Polymer Science, third ed., John Wiley and Sons, New York, USA, 1984.

[24] M. Lopretti, E. Martinez, L. Torres, R. Perdomo, M. Santos, A. Rodrigues, Influence of nitrogen/carbon ratio and complementary sugars on dextransucrase production by Leuconostoc mesenteroides NRRL B512(f), Process Biochem. 34 (1999) 879 884. 